\title{
Study of Mechanical, Tribological and Thermal Stability Properties of TiAIN Coatings with Low Aluminum
} \section{Content}

\author{
Enrique Camps ${ }^{1 *}$, Johans S. Restrepo ${ }^{2}$, Stephen Muhl ${ }^{2}$ and José G. Quiñones-Galván ${ }^{3}$ \\ 1. Departamento de Física, Instituto Nacional de Investigaciones Nucleares, Apartado Postal 18-1027, México D.F., C.P. 11801, \\ México \\ 2. Instituto de Investigaciones en Materiales, Universidad Nacional Autónoma de México, Apartado Postal 70-360, México, D. F., C. \\ P. 04510, México
}

3. Departamento de Física, CUCEI, Universidad de Guadalajara, CP 44430, Guadalajara, Jalisco, México

\begin{abstract}
Ti-Al-N coatings have been widely studied especially those with high aluminum content for different industrial applications because they have high wear resistance and good thermal stability. For the present work TiAlN thin films were prepared by the simultaneous laser ablation of $\mathrm{Ti}$ and $\mathrm{Al}$ targets in a reactive atmosphere containing nitrogen. The structural characterization of the deposits was carried out using X-ray diffraction and it was found that the films were highly oriented in the (111) direction of TiN. The maximum coating hardness was $43 \mathrm{GPa}$ for an aluminum concentration close to 11 at.\%, whilst the coatings commonly used in industry with an aluminum content of about 25 at.\% or greater, have hardness values between 25 and $30 \mathrm{GPa}$. The thermal stability of the films was studied by micro-Raman spectroscopy in the temperature range from 500 to $900{ }^{\circ} \mathrm{C}$. This technique was used to detect the formation of the $\mathrm{TiO}_{2}$ phase. The results indicated that the inclusion of relatively low aluminum contents up to 15 at.\% led to an improved thermal stability up to $900{ }^{\circ} \mathrm{C}$.
\end{abstract}

Key words: TiAlN thin films, laser ablation, hardness, thermal stability, tribology.

\section{Introduction}

Titanium nitride is a material widely used as a protective coating due to its good mechanical and tribological properties, including high hardness and good wear resistance $[1,2]$. Improving the properties of TiN by adding other elements such as $\mathrm{Si}$ or $\mathrm{Al}$ has been extensively studied [3]. In particular the incorporation of $\mathrm{Al}$ in the $\mathrm{TiN}$ lattice to form the ternary alloy TiAlN has proved to enhance hardness of TiN films, besides TiAlN has better oxidation resistance and its thermal stability is higher than that of TiN [3-5].

It is known that TiN decomposes into rutile $\mathrm{TiO}_{2}$ when it is exposed to temperatures above $500{ }^{\circ} \mathrm{C}$ in

*Corresponding author: Enrique Camps, Dr., research fields: plasma physics, thin films and laser ablation. air [6-8], and this limits its applications for high temperature applications. When $\mathrm{Al}$ is added to $\mathrm{TiN}$ a metastable TiAlN alloy is obtained and the oxidation resistance is improved (up to $800^{\circ} \mathrm{C}$ ) [6]. A thin $\mathrm{Al}_{2} \mathrm{O}_{3}$ layer forms on the surface preventing the diffusion of oxygen into the film, avoiding the formation of the rutile $\mathrm{TiO}_{2}$ phase.

TiAlN thin films are mainly prepared using techniques such as CVD [9], sputtering [6, 10] and cathodic arc deposition[11, 12]. Reports on the deposition of TiAlN thin films by pulsed laser deposition have been published [13, 14] involving the ablation of targets with a mixture of $\mathrm{Ti}$ and $\mathrm{Al}$ in a nitrogen containing atmosphere. Acquaviva et al. [13] obtained a polycristalline mixture of TiN and different TiAlN phases. In the case of the experiments reported by Lackner et al. [14] TiAlN films were obtained 
oriented in the (200) and (220) directions of TiN structure and a maximum hardness of $35 \mathrm{GPa}$ for an aluminum concentration of $23 \%$ in the films was reported. The mixture of orientations in the films affect the hardness of TiN thin films, the highest hardness value is reached when the TiN is oriented in the (111) direction [15], this results were reproduced for TiAlN thin films, thus it is desirable to have (111) highly oriented thin films in order to reach a maximum hardness. Authors are not aware of reports in literature where low $\mathrm{Al}$ concentrations (below 15 at.\%) are used except for one sample with $\sim 12.7$ at.\% of aluminum with hardness of $19.9 \mathrm{Gpa}$ [14].

In the present paper a different approach was employed to deposit TiAlN thin films. Two high purity targets ( $\mathrm{Ti}$ and $\mathrm{Al}$ ) were ablated at the same time in an atmosphere containing nitrogen. The experimental conditions on the Ti target were kept constant, whilst on the Al target they were changed. Under such conditions the Al content in the films could be controlled quite precisely so that the changes in the properties of the films could be carefully studied. In particular, the regimes of low Al contents (up to 15 at.\%) were of interest for the present work, as they are not well studied.

\section{Experimental Setup}

TiAlN thin films were obtained by the simultaneous ablation of high purity $\mathrm{Ti}$ and $\mathrm{Al}$ targets. The laser ablation system shown in Fig. 1, was described in detail in [16] and consisted of a vacuum chamber evacuated to a base pressure of $2.6 \times 10^{-4} \mathrm{~Pa}$ with a turbomolecular pump. During the deposition, the chamber was backfilled with a gas mixture of $60 / 40$ $\mathrm{Ar} / \mathrm{N}_{2}$ to a working pressure of $1.06 \mathrm{~Pa}$. The substrates were heated to a temperature of $200{ }^{\circ} \mathrm{C}$, and a 1064 $\mathrm{nm} \mathrm{Nd}$ :YAG laser with a maximum output energy of $500 \mathrm{~mJ}, 5 \mathrm{~ns}$ pulse width and frequency of $10 \mathrm{~Hz}$ was used for the ablation process. The laser beam was divided into two equal beams, one directed towards the Ti target and the other to the $\mathrm{Al}$ target.
For the deposition polished SS 304 substrates were used. Prior to the deposition the substrates were nitrided in order to increase the hardness and thus decrease the hardness gradient between the substrate and the deposits, improving the adhesion of the films to the substrates; the nitriding process is described elsewhere [17]. The substrates were placed perpendicularly in front of the titanium target at $6 \mathrm{~cm}$. The distance between the laterally placed aluminum target to the substrate was varied from 2.5 to $5 \mathrm{~cm}$, see Fig. 1. The deposition time was adjusted to obtain an average sample thickness of $700 \pm 50 \mathrm{~nm}$ measured by a profilometer TENCOR KLA D-120.

The plasma parameters, such as mean kinetic ion energy and plasma density, of the plasmas produced during the ablation of each of the targets, were measured using a $6 \mathrm{~mm}$ diameter $1 \mathrm{~mm}$ thick planar Langmuir probe [16]. During the measurements, the probe was located in the position of the substrates, and was removed during the deposition process.

The laser fluence on the Ti target was kept fixed at $7 \mathrm{~J} / \mathrm{cm}^{2}$ in order to maintain a constant mean kinetic Ti ion energy of $300 \mathrm{eV}$ and a plasma density of $1.4 \times$ $10^{17} \mathrm{~m}^{-3}$. For the plasma produced by the ablation of $\mathrm{Al}$, the fluence was varied such that the mean kinetic $\mathrm{Al}$ ion energy remained constant at a value of $100 \mathrm{eV}$ but the plasma density was varied from $9 \times 10^{15}$

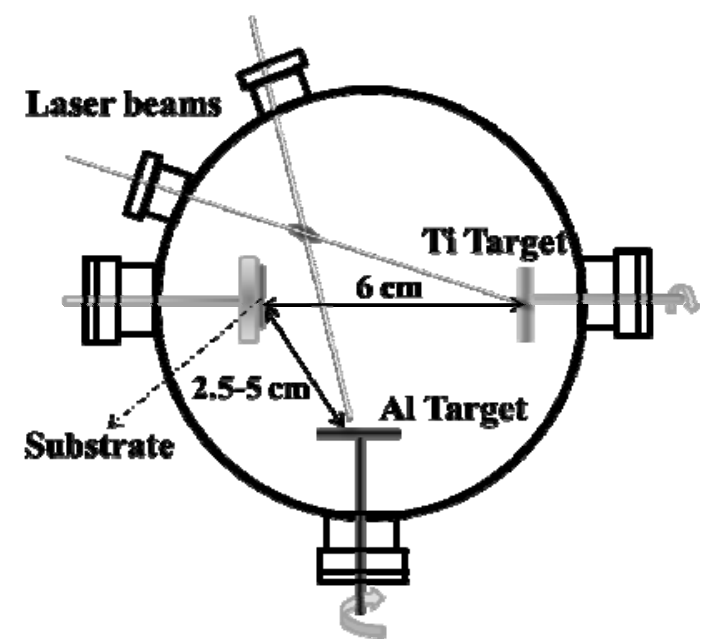

Fig. 1 Experimental arrangement of the simultaneous laser ablation. 
to $43 \times 10^{15} \mathrm{~m}^{-3}$. The variation of the plasma density produced a change in the $\mathrm{Al}$ content in the TiAlN films, such that there was a linear relationship between the plasma density and the $\mathrm{Al}$ content [16].

The chemical composition of the deposits was measured using an Oxford 3608 EDS (Energy dispersive spectroscopy) equipment installed in a JEOL 5900LV SEM (Scanning electron microscope). Some of the samples were measured by XPS in order to confirm the EDS results that showed that the Al content in the samples varied from 2 up to 15 at.\%. The structural properties of the films were measured by X-ray diffraction using a Siemens D-5000 diffractometer.

The mechanical and tribological properties were measured as a function of the $\mathrm{Al}$ concentration. The hardness of the films was measured by nanoindentation using a CSM Nanohardness Tester with a Berkovich diamond tip and in these measurements the load was chosen so that the penetration depth did not exceed the $10 \%$ of the total thickness of the samples. The plasticity index (H/E) and the resistance to plastic deformation $\left(\mathrm{H}^{3} / \mathrm{E}^{2}\right)$ were calculated from the obtained data.

The friction coefficient was measured in a reciprocating CETR UMT wear tester at $2 \mathrm{~N}$ of normal force with a track length of $10 \mathrm{~mm}$, at a frequency of $5 \mathrm{~Hz}$ during $10 \mathrm{~min}$ using $10 \mathrm{~mm}$ diameter alumina balls, after the tests the dimensions of the wear track was measured using a profilometer TENCOR KLA D-120.

The thermal stability of the samples was analyzed using microRaman spectroscopy with a Horiba Jobin Yvon HR 800 Raman spectrometer where the $532 \mathrm{~nm}$ excitation line beam was focused using a 50X objective lens. A programmable oven placed on the microRaman stage was used to perform annealing treatments from 500 to $900{ }^{\circ} \mathrm{C}$ in air at $100{ }^{\circ} \mathrm{C}$ steps, the temperature for each measurement was held constant for 20 min, during this time the Raman spectra were obtained for each temperature.

\section{Experimental Results}

\subsection{Structural and Mechanical Characterization}

Fig. 2 shows part of the XRD spectra, the straight line corresponds to the XRD TiN reference sample. It can be seen that the samples have a preferred orientation in the (111) direction of TiN and a fcc $\mathrm{B} 1-\mathrm{NaCl}$ structure of the spacial group Fm-3m. No other diffraction peaks were observed. The preferred orientation was probably due to the bombardment of the growing films which can produce a channeling effect [18] whereby the re-sputtering from certain lattice planes is minimized.

On the fcc- $\mathrm{NaCl}$ structure the plane (111) is the most dense plane, and this explains the coating preferred orientation. The group of J.M. Lackner [14] deposited TiAlN coatings by PLD using a $\mathrm{Ti} / \mathrm{Al}=1$ target, and obtained polycrystalline coatings, as they were deposited in a pure nitrogen atmosphere and at room temperature. The TiN peak of the (111) plane is located at $2 \theta=36.02^{\circ}$ and corresponds to a lattice parameter of $4.31 \AA$. From Fig. 2, it can be seen that as $\mathrm{Al}$ was incorporated the peak shifted to higher angles, meaning that the lattice of TiN is being distorted by $\mathrm{Al}$, and indicating that $\mathrm{Al}$ atoms substitute $\mathrm{Ti}$ atoms in the TiN lattice [14]. As the aluminum content increased from 2.0 to 11.6 at.\%, the lattice

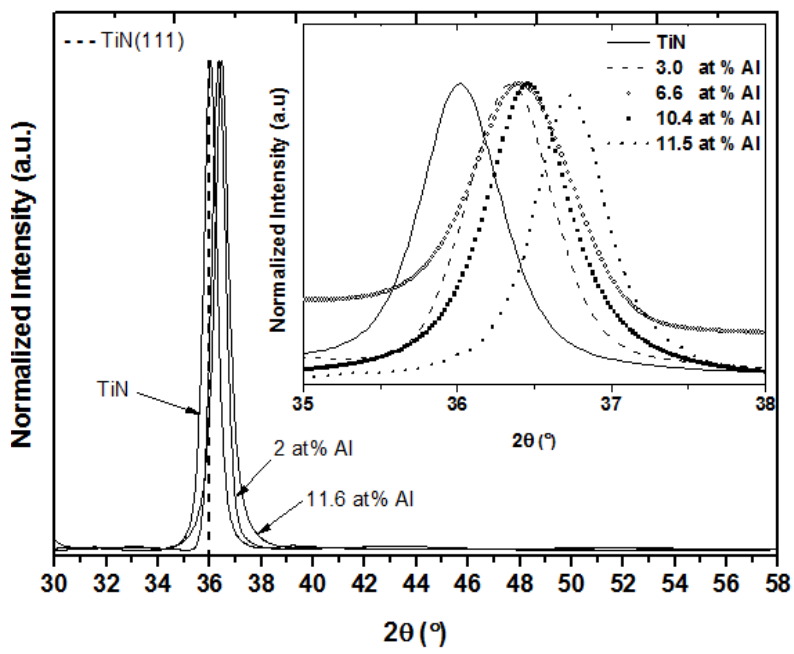

Fig. 2 XRD patterns of TiAIN thin films for different Al concentrations. 


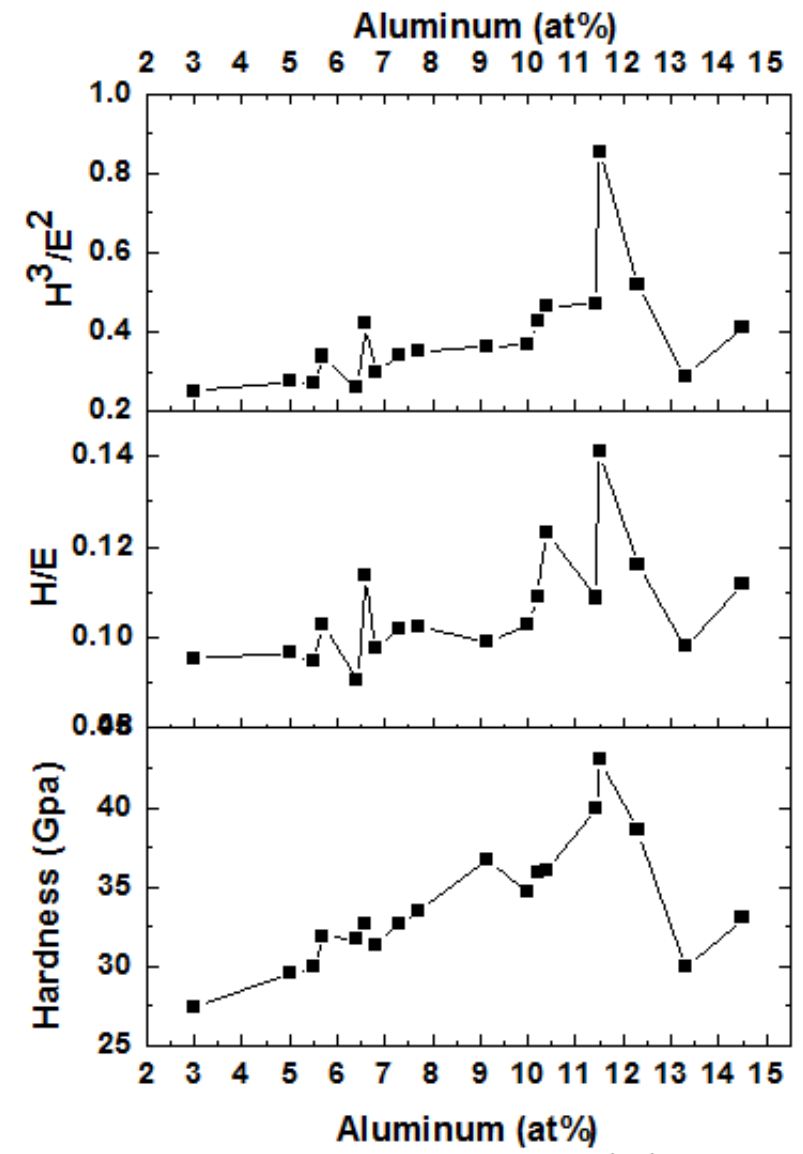

Fig. 3 Plastic deformation resistance $\left(\mathrm{H}^{3} / \mathrm{E}^{2}\right)$, plasticity index (H/E) and hardness of TiAIN thin films, as a function of the aluminum content.

parameter decreased from 4.28 to $4.23 \AA$.

The films hardness, plasticity index $(\mathrm{H} / \mathrm{E})$ and plastic deformation resistance $\left(\mathrm{H}^{3} / \mathrm{E}^{2}\right)$ are shown in Fig. 3 as a function of $\mathrm{Al}$ concentration. The hardness of the films increased as Al was incorporated, reaching a maximum value of $43 \mathrm{GPa}$ for the sample with 11.5 at.\%, and this is considerably greater than the reported values for this material [12, 14]. For Al concentrations greater than 11.5 at.\% the hardness value decreased. The reports in the literature indicate that the values of hardness and elastic modulus are typically around $30 \mathrm{GPa}$ and $350 \mathrm{Gpa}$, or lower values for high aluminum content of more than 20 at.\% [14, 19]. Musil [3] reported hardness values greater than $40 \mathrm{Gpa}$, but the coatings were grown by magnetron sputtering with high ion bombardment and they suggested that a nanocomposite of nano-crystalline
TiAlN and AlN was formed, with the AlN in the grain boundaries. Furthermore, the $\mathrm{Al}$ concentrations that they obtained were more than 20 at.\% $[3,14,18]$ and they obtained mixtures of the (111) and (200) orientations.

Frequently the hardness or the modulus of elasticity has no direct relationship with the wear resistance or friction coefficient of thin films but there is a relation with the $\mathrm{H} / \mathrm{E}$ or $\mathrm{H}^{3} / \mathrm{E}^{2}$ ratios [20]. The plasticity index describes elastic failure related with the cracking resistance (toughness indicative) and plastic deformation resistance describes the creep resistance on a ball/plane contact [20].

The results showed that the H/E ratio of the films shows the same trend as the hardness. Musil [21] reported that films with values of $\mathrm{H} / \mathrm{E}>0.1$ have enhanced toughness. The values of toughness shown in Fig. 3 are near to 0.1 and they increase as the $\mathrm{Al}$ content increases and reach a maximum value of $\mathrm{H} / \mathrm{E}$ $=0.14$ for the film with the maximum hardness at a value of 11.5 at. $\%$ of $\mathrm{Al}$ content. The same behavior was observed for $\mathrm{H}^{3} / \mathrm{E}^{2}$ obtaining a maximum value of 0.85. In reference [21] Musil reports a maximum value around 0.12 and 0.64 for the plastic index and plastic deformation resistance respectively for samples with $\mathrm{Al}$ content between 30 and 50 at.\%. The results obtained in the present study are similar to those reported by Musil, so that films with lower $\mathrm{Al}$ contents also could be expected to be hard and tough.

\subsection{Tribological Properties}

The friction coefficient is fairly large for all the samples, taking values between 0.63 and 0.7 , with no clear dependence on the aluminum content. The friction behavior observed for all samples showed an initial period of run-in, where the initial roughness is removed, forming wear particles that increase the friction coefficient, and after that a steady-state is reached [22], this period had a maximum duration of $90 \mathrm{~s}$ for the sample with 12.3 at.\% $\mathrm{Al}$ content. In references [23-26], samples with aluminum contents 
exceeding 20 at.\%, were studied in similar conditions and obtained friction coefficients between 0.65 and 0.8 , which are quite close to those obtained in the present study. Fig. 4 shows the coefficient of friction and wear rate as a function of the aluminum content. Samples with an aluminum content lower than 12 at.\% showed the lowest wear rate with values of about 5.6 $5.7 \times 10^{-6} \mathrm{~mm}^{3} / \mathrm{N} \cdot \mathrm{m}$. The 12 at. $\%$ aluminum content sample had a much higher wear rate of $117.25 \times 10^{-6}$ $\mathrm{mm}^{3} / \mathrm{N} \cdot \mathrm{m}$.

As such there appears too little relation between the mechanical properties of the samples with the tribological characteristics. The work of Erdemir A. [27] may help explain the tribological results. $\mathrm{He}$ reported that the probability of formation of oxides during the wear tests can determine the friction coefficient. The important factor is the ion potential which is the ratio between the ionic radius and the oxidation state of the metal, and when the ion potential increases, the friction coefficient decreases. Titanium and aluminum oxide have ion potentials of 5.8 and 5.6 respectively, which individually should give a low friction coefficient, but when these two oxides are mixed the difference between their ionic potential is what determines the friction coefficient. This difference is low (0.2) and therefore, based on these ideas, a high friction coefficient could be expected for TiAlN. On the other hand, the alumina counterpart used in these measurements causes a greater adhesion force with the coating exposed to wear. When stainless steel $100 \mathrm{Cr} 6$ or silicon nitride counterparts are used, it is possible to obtain lower coefficients of friction [26].

In help to understand the behavior of the wear process as a function of the $\mathrm{Al}$ content we studied the chemical changes that occurred on the surfaces of the samples during the pin-on-disc tests. The 5.5 at. $\%$ of $\mathrm{Al}$ and 12.3 at.\%, samples were selected for the Raman spectroscopy analysis, and the results are given in Figs $5 \mathrm{a}$ and $5 \mathrm{~b}$, respectively. In the as-deposited spectra from the 5.5 at.\% $\mathrm{Al}$ film the

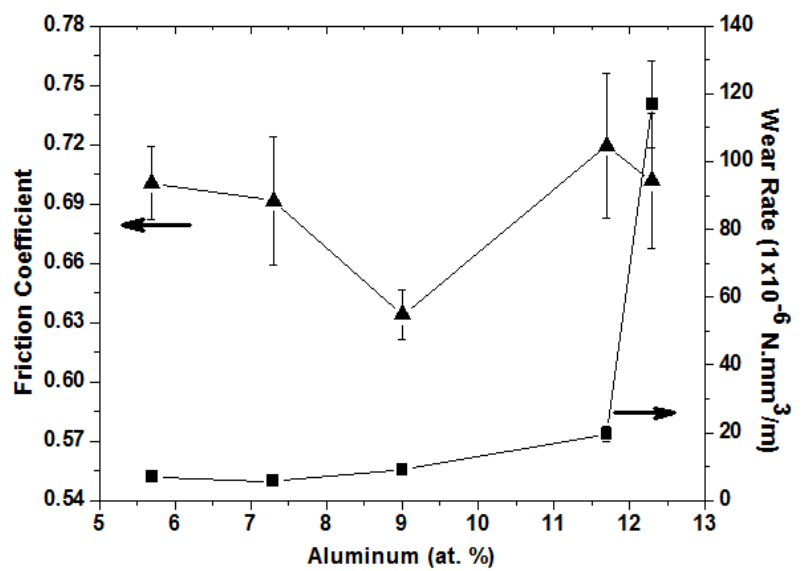

Fig. 4 Coefficient of friction and wear rate, as a function of aluminum content.

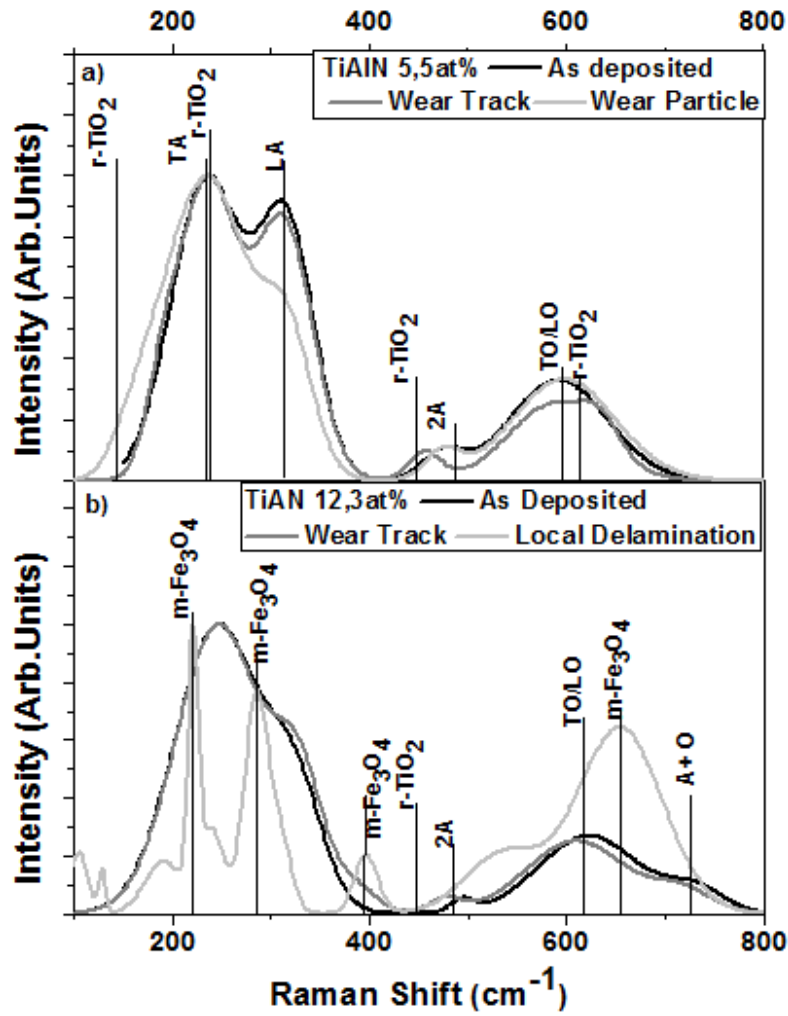

Fig. 5 Raman spectra of TiAIN films before and after the wear tests, for two samples with different aluminum content: a) 5.5 at. \% and b) 12.3 at.\%.

transversal and longitudinal acoustic modes (TA and LA at 235 and $313 \mathrm{~cm}^{-1}$ ) associated to the acoustic dispersion by the titanium and aluminum atoms could be observed. Additionally, the bands appearing above $400 \mathrm{~cm}^{-1}$ correspond to the acoustic modes of second order (2A), and the transverse and longitudinal optical modes (TO and LO) [28]. The spectrum of the wear 

TiAIN Coatings with Low Aluminum Content

track also showed the typical signals for the TiAlN compound (i.e., the TA, LA, TO and LO bands), but bands at 450 and $613 \mathrm{~cm}^{-1}$ were also observed and were identified as vibrations from the rutile phase of $\mathrm{TiO}_{2}$, that produced a deformation of the TO, LO bands. Wear debris was also observed inside the wear track, and from the Raman spectra this was identified as containing TiAlN particles which since there was a broadening of the acoustic bands, due to the presence of rutile vibrations at 143 and $236 \mathrm{~cm}^{-1}$, were probably partially oxidized or contained a higher concentration of aluminum, see below. Fig. 5b shows the Raman spectra from the 12.3 at.\% of Al sample. For the as-deposited material the previously mentioned TA, LA, TO and LO bands were observed. The overlap of the TA and LA bands is due to the higher aluminum content and to the increase of defect density in the network. A shift of the TO, LO and $\mathrm{A}+\mathrm{O}$ bands was also observed and is again typical for high $\mathrm{Al}$ content TiAlN [17]. Localized delamination of the coating in the wear track occurred during the pin-on-disc tests, and the Raman spectra of these areas showed the presence of iron oxides in magnetite phase $\left(\mathrm{m}-\mathrm{Fe}_{3} \mathrm{O}_{4}\right)$. The spectra of the non delaminated parts of the wear track showed that the TA and LA bands did not change, whilst the TO, LO and $2 \mathrm{~A}$ bands shifted towards lower wave numbers, probably due to the deformation of the material or to the increase of defects in the nitrogen positions inside the network. The thermal stability of this sample was improved since $\mathrm{TiO}_{2}$ was not detected, but the higher $\mathrm{Al}$ content appeared to produced an increase of the shear resistance, and therefore increase the surface fatigue, which in turn produced the local delamination $[22,27]$ and the observed higher values of the wear rate (see Fig. 4).

These results indicate that the lower aluminum content samples had less resistance to oxidization during the wear tests, which reduced the shear resistance in the film and therefore the coating could better withstand the load, yielding lower wear rates (see Fig. 4). For the samples with aluminum content $\geq$ 12 at.\%, although they had better mechanical properties (see Fig. 3) the increase of the shear resistance, due to the lack of oxidation, produced greater distortion of the coating down to the interface coating/substrate, which resulted in delamination and higher wear rates (see Fig. 4).

\subsection{Thermal Stability}

The thermal stability of the TiAlN films was studied by Raman spectroscopy to evaluate the oxide formation. Fig. 6 shows the Raman spectra of samples with different amounts of aluminum after annealing at $500{ }^{\circ} \mathrm{C}$ in air. As can be seen the TiN reference was transformed into a mixture of $\mathrm{TiO}_{2}$ phases and some residual bands corresponding to the TiN. When small

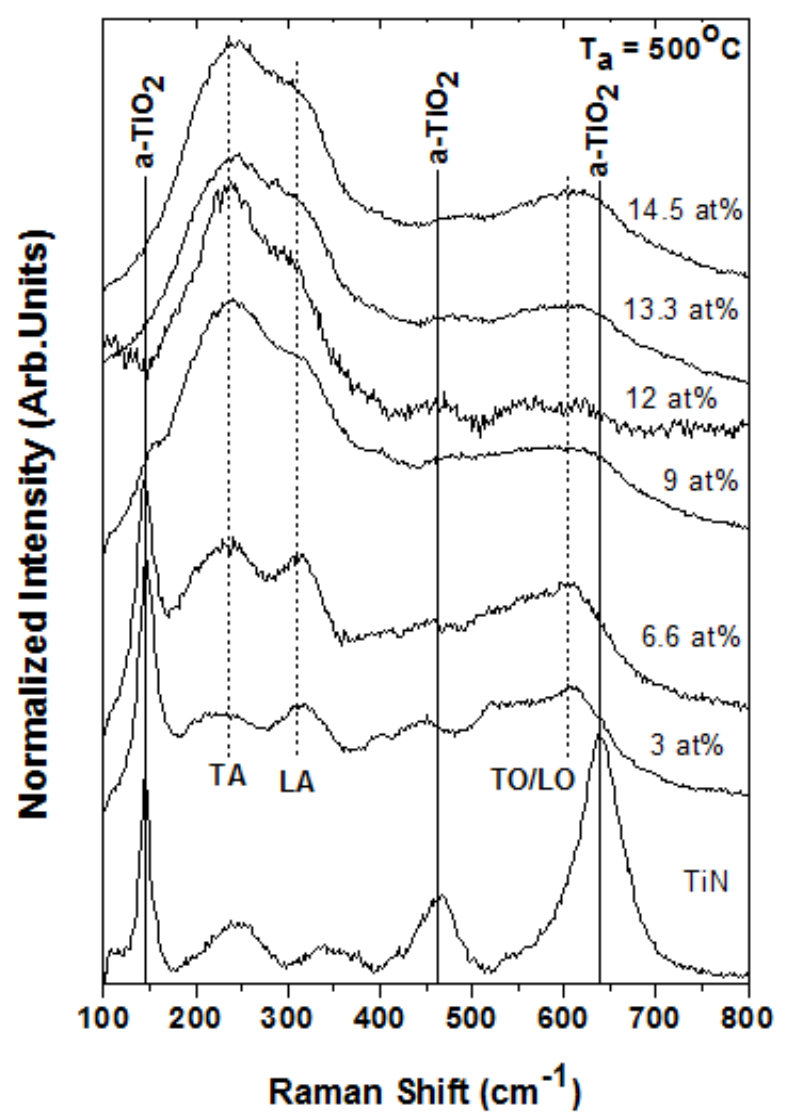

Fig. 6 Raman spectra of samples with different aluminum content annealed at $500{ }^{\circ} \mathrm{C}$. ( $\mathrm{r}-$ ) indicates the position of the rutile bands, (a-) indicates the position of the anatase bands and (TA, LA and TO/LO) indicates the position of the characteristic bands of the TiAIN compound. 
amounts of $\mathrm{Al}$ were incorporated, for example, 3 and 6.6 at. $\%$, the bands corresponding to the $\mathrm{TiO}_{2}$ are also observed, although their intensity is lower than for the TiN. As the Al content was increased the intensity of the $\mathrm{TiO}_{2}$ bands decreased up to values $>9$ at. $\%$ of $\mathrm{Al}$, where they were no longer detected. For samples with $12,13.3$ and 14.5 at.\% the annealing temperature had little effect on the Raman spectra, indicating that the addition of $\mathrm{Al}$ improved the oxidation resistance and thermal stability of TiN.

A comparison of the thermal stability of the samples deposited by magnetron sputtering and industrial cathodic arc evaporation with $\mathrm{Al}$ content $>$ 20 at.\% [29, 30] with the samples from the present study shows that the thermal stability is similar, but in our work the $\mathrm{Al}$ content was much lower; between 9 and 14.5 at.\%. Similarly, the authors of reference [29] studied the effect of the aluminum contents greater than 10 at.\% on the oxidation resistance of TiAlN samples at $900{ }^{\circ} \mathrm{C}$. They concluded that the best oxidation resistance was obtained for samples with 20-35 at.\%, again considerably larger than the present study.

Fig. 7 shows the Raman spectra of a 12 at.\% TiAlN thin film annealed at temperatures from 500 up to $900{ }^{\circ} \mathrm{C}$, in order to further compare our work with that of Pfeiler M. [29] and Man B.Y. [30]. It can be observed that apart from a small increase in the $\sim 460 \mathrm{~cm}^{-1}$ rutile $\mathrm{TiO}_{2}$ signal, there was little change in the Raman spectra until the anneal temperatures were $>$ $700{ }^{\circ} \mathrm{C}$. At $800{ }^{\circ} \mathrm{C}$, a small band related to $\mathrm{TiO}_{2}$ at $150 \mathrm{~cm}^{-1}$ could be observed, and at $900{ }^{\circ} \mathrm{C}$ two bands associated with anatase $\mathrm{TiO}_{2}$ were present at 400 and $500 \mathrm{~cm}^{-1}$ in the spectrum. However, the TiN bands were still present in the spectrum, which means that even at $900{ }^{\circ} \mathrm{C}$ the TiAlN thin film was not completely transformed into $\mathrm{TiO}_{2}$. On the other hand other reports, X-ray diffraction and Raman spectroscopy measurements showed that the TiAlN coatings with Al contents $>20$ at. $\%$ were completely oxidized to rutile $\mathrm{TiO}_{2}[29,30]$.

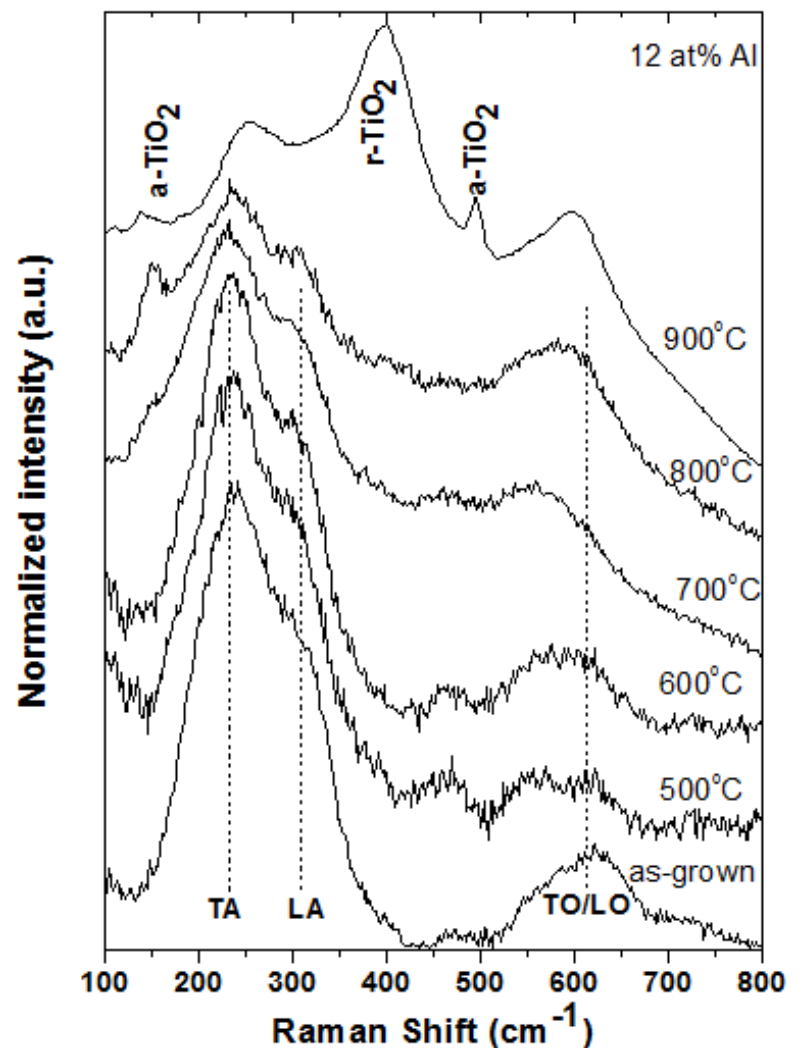

Fig. 7 Raman spectra of a TiAlN sample with 12 at.\% of $\mathrm{Al}$, at different annealing temperatures.

\section{Conclusions}

By using the simultaneous laser ablation of two targets ( $\mathrm{Ti}$ and $\mathrm{Al}$ ) in a reactive atmosphere containing nitrogen, it was possible to deposit thin films of the ternary compound TiAlN, with low aluminum contents in the range between 3 and 15 at.\%. The films showed a good thermal stability, improving their resistance to the formation of $\mathrm{TiO}_{2}$, even when the lowest values of aluminum content ( 3 at.\%) were used. It was evident that the higher aluminum content, the better thermal stability was observed, however the mechanical properties had an optimum value at an aluminum content around 11 at.\%, reaching a hardness of $43 \mathrm{GPa}$.

The friction coefficient did not show a clear trend with the aluminum content, as these values varied in the range between 0.61 and 0.75 for the different quantities of aluminum. It was observed that for low aluminum contents $(<10$ at.\%), the wear rate was 

TiAIN Coatings with Low Aluminum Content

about $8 \times 10^{-6} \mathrm{~N} \mathrm{~mm}^{3} / \mathrm{m}$, but when the aluminum content was increased the wear rate achieved values higher than $1 \times 10^{-4} \mathrm{~N} \mathrm{~mm}^{3} / \mathrm{m}$. This difference can be due to the fact that samples with low aluminum contents produce $\mathrm{TiO}_{2}$ (rutile) inside the wear track (during the wear tests), which is responsible of the reduction of the shear resistance, whilst in the case of the higher aluminum contents ( $>10$ at. $\%$ ), the $\mathrm{TiO}_{2}$ is not formed, and this produces a higher fatigue and local delamination. Comparing with other references, it was not observed the formation of aluminum oxide, neither inside the wear track, nor during the thermal stability tests, which can be due to the low quantities of aluminum used in this investigation

\section{Acknowledgments}

This work was partially supported by CONACYT under contract No. 128732.

\section{References}

[1] Kim, S. H., Park, H., Lee, K. H., Jee, S. H., Kim, D. J. and Yoon, Y. S. et al. 2009. "Structure and Mechanical Properties of Titanium Nitride Thin Films Grown by Reactive Pulsed Laser Deposition.” J. Ceram. Process. Res. 10 (1): 49-53.

[2] Jaeger, D. and Patscheider, J. 2012. "A Complete and Self-Consistent Evaluation of XPS Spectra of TiN." Journal of Electron Spectroscopy and Related Phenomena 185: 523-34.

[3] Chen, L., Dua, Y., Wang, S. Q., Wang, A. J. and Xua, H. H. 2009. "Mechanical Properties and Microstructural Evolution of TiN Coatings Alloyed with $\mathrm{Al}$ and Si."Mater. Sci. Eng. A 502: 139-43.

[4] Rachbauer, R., Mass, S., Stergar, E., Holec, D., Kiener, D. and Keckes, J. et al. 2011. "Decomposition Pathways in Age Hardening of Ti-Al-N Films." J. Appl. Phys. 110: 023515-1-15.

[5] Wüstefeld, Ch., Rafaja, D., Dopita, M., Motylenko, M., Baehtz, C. and Michotte, C. et al. 2011. "Decomposition Kinetics in $\mathrm{Ti}_{1-\mathrm{x}} \mathrm{Al}_{\mathrm{x}} \mathrm{N}$ Coatings as Studied by In-Situ X-Ray Diffraction during Annealing." Surf. Coat. Technol. 206: 1727 -34.

[6] Musil, J. and Hruby, H. 2000. "Superhard Nanocomposite $\mathrm{Ti}_{1-\mathrm{x}} \mathrm{Al}_{\mathrm{x}} \mathrm{N}$ Films Prepared by Magnetron Sputtering." Thin Solid Films 365: 104-9.

[7] Hsieh, J. H., Tan, A. L. K. and Zeng, X. T. 2006. "Oxidation and Wear Behaviors of Ti-Based Thin Films."
Surf. Coat. Technol. 201 (7): 4094 -8.

[8] Chen, L., Paulitsch, J., Du, Y. and Mayrhofer, P. H. 2012. "Thermal Stability and Oxidation Resistance of Ti-Al-N Coatings." Surf. Coat. Technol. 206: 2954-60.

[9] Hauert, R. and Patscheider, J. 2000. "From Alloying to Nanocomposites-Improved Performance of Hard Coatings." Adv. Eng. Mater. 2 (5): 247-59.

[10] Subramanian, B., Ashok, K., Kuppusami, P., Sanjeeviraja, C. and Jayachandran, M. 2008. "Characterization of Reactive DC Magnetron Sputtered TiAlN Thin Films." Cryst. Res. Technol. 43 (10): 1078-82.

[11] Danişman, Ş., Savaş, S. and Topal, E. S. 2008. "Comparison of Wear Behaviours of Cathodic Arc TiN, TiAlN Coated and Uncoated Twist Drills Under Aggressive Machining Conditions." Tribology in Industry 30 (1 \& 2): 17-22.

[12] Chun, S. Y., Lee, C. H. and Lee, S. J. 2007. "Properties of TiAl and TiAlN Thin Films by Pulsed Cathodic ARC." Mater. Sci. Forum. 534-536: 1413-6.

[13] Acquaviva, S., D’Anna, E., Elia, L., Fernández, M., Leggieri, G. and Luches, A. et al. 2000. "Characterization of TiAlN Films Deposited by Reactive Pulsed Laser Ablation."Thin Solid Films 379: 45-9.

[14] Lackner, J. M., Waldhauser, W., Ebner, R., Keckés, J. and Schöberl. T. 2004. "Room Temperature Deposition of ( $\mathrm{Ti}, \mathrm{Al}) \mathrm{N}$ and $(\mathrm{Ti}, \mathrm{Al})(\mathrm{C}, \mathrm{N})$ Coatings by Pulsed Laser Deposition for Tribological Applications." Surf. Coat. Technol. 177-178: 447-52.

[15] Escobar-Alarcón, L., Camps, E., Castro, M. A., Muhl, S. and Mejia-Hernández, J. A. 2005. "Effect of the Plasma Parameters on the Properties of Titanium Nitride Thin Films Grown by Laser Ablation." Appl. Phys. A 81: 1221-6.

[16] Quiñones-Galván, J. G., Camps, E., Muhl, S., Flores, M. and Campos-González, E. 2014. "Influence of Plasma Density on the Chemical Composition and Structural Properties of Pulsed Laser Deposited TiAlN Thin Films." Physics of Plasmas 21: 053509-1-5.

[17] Camps, E., Becerril, F., Muhl, S., Alvarez-Fregoso, O. and Villagrán, M. 2000. "Microwave Plasma Characteristics in Steel Nitriding Process." Thin Solid Films 373: 293-8.

[18] Luth, H. 2010. Surfaces and Interfaces of Solid Materials. Edited by Springer.

[19] Shimizu, T., Komiya, H., Watanabe, T., Teranishi, Y., Nagasaka, H. and Morikawa, K. et al. 2014. "HIPIMS Deposition of TiAlN Films on Inner Walls of Micro-Dies and Its Applicability in Micro-Sheet Metal Forming." Surface \& Coatings Technology 250: 44-51.

[20] Leyland, A. and Matthews, A. 2000. "On the Significance of the H/E Ratio in Wear Control: A Nanocomposite Coating approach to Optimised Tribological Behavior." 

TiAIN Coatings with Low Aluminum Content

Wear 246: 1-11.

[21] Musil, J. 2012. "Advanced Hard Nanocomposite Coatings with Unique Properties." Surf. Coat. Technol. 207: 50-65.

[22] Holmberg, K. and Matthews, A. 2009. COATINGS TRIBOLOGY Properties, Techniques and Applications in Surface Engineering. ELSEVIER SCIENCE B. V. Great Britain.

[23] Zhao, H., Wang, X-H., Liu, Q-L., Chen, L-J. and Liu, Z. 2010."Structure and Wear Resistance of TiN and TiAlN Coatings on AZ91 Alloy Deposited by Multi-Arc Ion Plating." Trans. Non ferrous Met. Soc. China 20: 679-82.

[24] Cano, M. F., Restrepo, J. S., Ruden, A., González, J. M. and Sequeda, F. 2009. "Effect of the Substrate Temperature on the Tribological Properties of TiAlN Coatings." In Proceedings of the 52nd Annual Technical Conference, Santa Clara, CA. 37-43.

[25] Mo, J. L., Zhu, M. H., Lei, B., Leng, Y. X. and Huang, N. 2007. "Comparison of Tribological Behaviours of AlCrN and TiAlN Coatings-Deposited by Physical Vapor
Deposition." Wear 263: 1423-9.

[26] Ramadoss, R., Kumar, N., Pandian, R., Dash, S., Ravindran, T. R. and Arivuoli, D. et al. 2013. "Tribological Properties and Deformation Mechanism of TiAlN Coating Sliding with Various Counterbodies." Tribology International 66: 143-9.

[27] Erdemir, A. 2000. "A Crystal-Chemical Approach to Lubrication by Solid Oxides." Tribology Letters (2-3): 97-102.

[28] Constable, C. P., Yarwood, J. and Munz, W. D. 1999. "Raman Microscopic Studies of PVD Hard Coatings." Surf. Coat. Technol. 155: 116-9.

[29] Pfeiler, M., Zechner, J., Penoy, M., Michotte, C., Mitterer, C. and Kathrein, M. 2009. "Improved Oxidation Resistance of TiAlN Coatings by Doping with Si or B." Surf. Coat. Technol. 203: 3104-10.

[30] Chawla, V., Chawla, A., Sidhu, B. S., Prakash, S. and Puri, D. 2000. "Oxidation Behavior of Nanostructured TiAlN and AlCrN Thin Coatings on ASTM-SA213-T-22 Boiler Steel." JMMCE 9 (11): 1037-57. 